\title{
Improved model for investigating transient stability in multimachine power systems
}

\author{
Ali Hamzeh, Zakaria Al-Omari \\ Electrical Engineering Department, Faculty of Engineering, Al-Ahliyya Amman University, Jordan
}

\begin{tabular}{l} 
Article Info \\
\hline Article history: \\
Received May 21, 2018 \\
Revised Jul 27, 2018 \\
Accepted Aug 10, 2018 \\
\hline
\end{tabular}

\section{Keywords:}

Computer program

Multimachine power system

Transient stability

Universal algorithm

\begin{abstract}
The determinant factor in transient stability study of electric power systems is the behavior of synchronous generators when subjected to sudden and large disturbances. The objective of this paper is to develop a mathematical model, general algorithm, and a computer program to investigate the transient stability of multi-machine power systems. The developed mathematical model is established as a first step. The new developments lie in modeling the fault occurrence and fault clearance as well as the procedure of computing the system matrices during and after the fault through only modification of the matrix before the fault. Based on the developed mathematical model, a general algorithm was built and translated into a computer program using an object-oriented and visual language called Delphi. The algorithm adopted the Runge-Kutta method for numerical solution of differential swing equations and was programmed within the program. The developed program was validated by applying it to small sample electrical networks. The program was used to analyze the transient stability of a relatively large test network and accurate results were obtained that could be relied upon for protective relays settings and optimization of control system parameters. It was found that the developed program is an effective and rapid tool for estimating transitory stability for real power systems.
\end{abstract}

Copyright $@ 2019$ Institute of Advanced Engineering and Science. All rights reserved.

\section{Corresponding Author:}

\section{Zakaria Al-Omari}

Electrical Engineering Departement, Faculty of Engineering,

Al-Ahliyya Amman University,

Zip code 19328, Amman, Jordan.

Email: zomari@ammanu.edu.jo

\section{INTRODUCTION}

The transient stability (TS) as a branch of rotor angle stability, refers to the ability of synchronous machines to maintain its synchronism after the electric power system has been subjected to a severe disturbance such as a shunt fault, sudden line outage or sudden connection or disconnection of large loads [1-5]. For disturbances such as faults, we are interested to find a critical clearing time that the faults are cleared without causing stability problems. To obtain the critical clearing time for a fault, we must solve the swing equations of the generators. The swing equation of a synchronous generator describes the dynamics of the machine, and it is a second-order differential equation [6].

There are various tools to investigate TS such as PSS-NETOMAC which is a Professional software for simulating electromagnetic and electromechanical power system transients [7], MATLAB/SIMULINK, Electrical Transient Analysis Program (ETAP), and DIgSILENT PowerFactory which offers among much more things, stability analysis functions (RMS) and electromagnetic transients (EMT) [8]. The professional programs are normally multifunctional software requiring significant time for the user to be familiar with, in addition to the high purchase or rent cost. MATLAB/SIMULINK can be used for studying TS but for relatively small power systems with limited number of machines [9]. The DIgSILENT PowerFactory 
software is capable to simulate all types of stability of power systems integrated with renewable energy sources [10-14]. In [15], the authors presented TS study for $400 \mathrm{kV}$ Iraqi grid focusing on load flow program and simple TS model using Modified Euler's method. [16] proposed a method for analyzing TS of a certain power system with 9 buses and 3 generators using generators closed loop transfer functions derived swing equations in Laplace domain. [17] introduces a TS approach which transform the multi-machine system to a simple one machine-infinite bus system. Various authors have proposed FACTS devices to improve the stability of multimachine power systems [18-21], and others proposed fuzzy controllers to stability enhancement [22].

In this paper, a new improved model is presented compared to classic models [23-25] to investigate the multimachine transient stability of power systems. The new model is characterized by the modeling of the fault occurrence and fault clearance as well as the procedure of computing the system matrices during and after the fault through only modification of the matrix before the fault.

\section{MATHEMATICAL MODEL}

Figure 1 represents an equivalent circuit of a multi-generator power system suitable for transient stability studies. The model contains $\mathrm{n}$ sources (synchronous generators and infinite buses) and a passive network having $\mathrm{m}$ buses. Each generator is represented by an equivalent circuit consisting of an electromotive force (emf) connected to one of the buses from 1 to $\mathrm{n}$, and a transient reactance integrated with the passive network. Thus, the total number of system buses is $\mathrm{m}+\mathrm{n}$. The passive network consists of reactances of generators, transformers, lines and loads that connect to each other to form $\mathrm{m}$ internal buses [26].

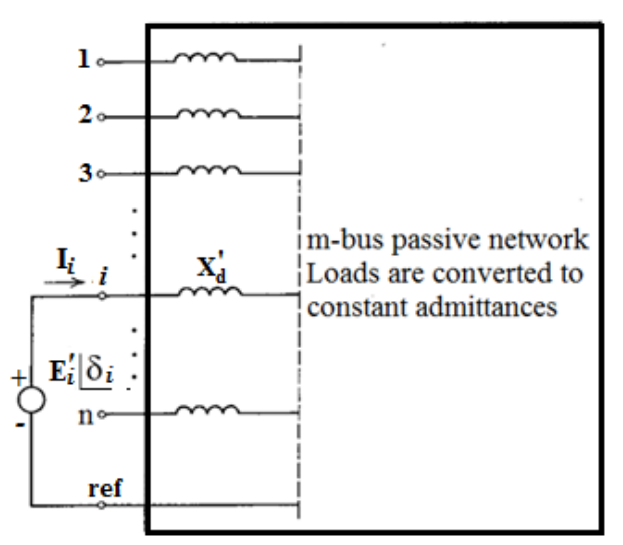

Figure 1. Power system model for multimachine transient stability studies

\subsection{Admittance Matrix of A Multimachine Power System}

The node voltage equation for any electric network with node 0 as reference is

$$
I_{b u s}=\left[Y_{b u s}\right] V_{b u s}
$$

where $I_{b u s}$ and $V_{\text {bus }}$ are vectors of injected bus currents and bus voltages respectively. [ $\left.Y_{b u s}\right]$ is the network bus admittance matrix which will be denoted as [Y'] in the following equations.

The node voltage equation for the network in Figure 1 is

$$
\left[\begin{array}{l}
I_{S} \\
0
\end{array}\right]=\left[Y^{\prime}\right]\left[\begin{array}{l}
E \\
V
\end{array}\right]
$$

Where,

$$
I_{S}=\left[\begin{array}{c}
I_{1} \\
\cdot \\
\cdot \\
\cdot \\
I_{n}
\end{array}\right]
$$


$0=$ Vector of $m$ zeros $(m \times 1)$

$$
\begin{aligned}
& E=\left[\begin{array}{c}
E_{1} \\
\cdot \\
\cdot \\
\cdot \\
E_{n}
\end{array}\right]=\text { Vector of emfs of } S G s \\
& \bar{E}_{i}=E_{i}^{\prime}{ } \delta_{i} \\
& V=\left[\begin{array}{c}
V_{n+1} \\
\cdot \\
\cdot \\
\cdot \\
V_{n+m}
\end{array}\right]=\text { Vector of internal buses voltages } \\
& {\left[Y^{\prime}\right]=\left[\begin{array}{cc}
{\left[Y_{n n}\right]} & {\left[Y_{n m}\right]} \\
{\left[Y_{m n}\right]} & {\left[Y_{m m}\right]}
\end{array}\right]}
\end{aligned}
$$

From (2) we obtain:

$$
\begin{aligned}
& 0=\left[Y_{m n}\right] E+\left[Y_{m m}\right] V \\
& V=-\left[Y_{m m}\right]^{-1}\left[Y_{m n}\right] E \\
& I_{s}=\left[Y_{n n}\right] E+\left[Y_{n m}\right] V \\
& I_{S}=\left\{\left[Y_{n n}\right]-\left[Y_{n m}\right]\left[Y_{m m}\right]^{-1}\left[Y_{m n}\right]\right\} E \\
& I_{S}=[Y] E
\end{aligned}
$$

Where,

$$
[Y]=\left[Y_{n n}\right]-\left[Y_{n m}\right]\left[Y_{m m}\right]^{-1}\left[Y_{m n}\right]
$$

$[\mathrm{Y}]$ is the so called reduced admittance matrix with the dimension $(\mathrm{n} \times \mathrm{n})$, where $\mathrm{n}$ is generators number. [Y] is computed for three cases: prefault, faulted, and postfault. The prefault matrix is used for computing the initial power angles, whereas the faulted matrix is used for the period from the fault occurrence at $\mathrm{t}=0$ until fault clearance at $t=T C$. The postfault matrix is required for $t>T C$.

The electrical real power injected into the system by a generator $i$ can be obtained in a similar way as power flow equations:

$$
P_{e i}=\sum_{j=1}^{n} E_{i}^{\prime} E_{j}^{\prime} Y_{i j} \cos \left(\delta_{i}-\delta_{j}-\theta_{i j}\right)
$$

Where,

$$
\bar{Y}_{i j}=Y_{i j} \angle \theta_{i j}
$$

For the system in steady state, the mechanical power input is equal to the electrical power output if losses are neglected, and we have

$$
P_{m i}=\sum_{j=1}^{n} E_{i}^{\prime} E_{j}^{\prime} Y_{i j}^{\prime} \cos \left(\delta_{i}-\delta_{j}-\theta_{i j}\right)
$$

\subsection{Swing Equations}

In the study of the transient stability of a generator-infinite bus simplified system, we assumed that the reference axis rotates at constant synchronous speed. In the case of the multi-machine system, we will 
consider that the reference axis is the rotor of a generator which rotates at a variable speed $\omega_{\text {ref }}$ over time. Thus, the swing equation for any generator:

$$
P_{m i}-P_{e i}=\frac{H_{i}}{\pi f}\left(\ddot{\delta}_{i}+\dot{\omega}_{r e f}\right) i=1, \ldots, n
$$

The above equation includes per unit (pu) quantities based on the common $S_{\text {base }}$. If $H_{G i}$ is the inertia constant of generator $i$ based on its rated $S_{G i}$, then $H_{i}$, which is inertia constant based on common $S$, is calculated by

$$
H_{i}=H_{G i} \frac{s_{G i}}{S_{B}}
$$

We select one of the generators as reference generator and we have

$$
\begin{aligned}
& i=r ; \delta_{i}=\delta_{r}=0 \\
& P_{m r}-P_{e r}=\frac{H_{r}}{\pi f} \dot{\omega}_{r e f} \\
& \therefore \dot{\omega}_{r e f}=\frac{\pi f}{H_{r}}\left(P_{m r}-P_{e r}\right)
\end{aligned}
$$

Now substituting (21) into (18), we have

$$
\ddot{\delta}_{i}=\frac{\pi f}{H_{r}}\left[\left(P_{m i}-\frac{H_{i}}{H_{r}} P_{m r}\right)-\left(P_{e i}-\frac{H_{i}}{H_{r}} P_{e r}\right)\right]
$$

If we select an infinite bus as reference, $H_{r}$ becomes $\infty$ and (22) becomes

$$
\ddot{\delta}_{i}=\frac{\pi f}{H_{r}}\left(P_{m i}-P_{e i}\right)
$$

Thus, the TS problem of a multi-machine power system leads to the problem of solving a system of $n$ second order non-linear differential equations that must be solved simultaneously. It is appropriate to transform these equations to a set of $2 \mathrm{n}$ first order nonlinear differential equations:

$$
\begin{aligned}
& \dot{\delta}_{i}=\alpha_{i} \\
& \dot{\alpha}_{i}=\frac{\pi f}{H_{i}}\left[\left(P_{m i}-\frac{H_{i}}{H_{r}} P_{m r}\right)-\left(P_{e i}-\frac{H_{i}}{H_{r}} P_{e r}\right)\right]
\end{aligned}
$$

$\alpha_{i}$ is the angular velocity deviation of the generator $i$ from the angular velocity of the reference generator. Since the Runge- Kutta method is the proper method to solve the differential equations, we will choose this method to solve the differential equations (24) and (25).

\section{ALGORITHM AND COMPUTER PROGRAM}

Based on the mathematical model and the algorithms we have already presented, we have designed a general algorithm that allows for the simulation of transient stability of electrical power systems, taking into account all generators Figure 2.

We have translated the developed algorithm into a computer program written in an objectiveoriented language Delphi. The program studies the multi-machine TS of an electric power system, which is modeled using data related to its components such as generators, transformers, lines and loads. We arranged the data into four tables as input files. The main interface of this program is shown in Figure 3.

By selecting the command "New", a window containing the four system tables is opened. The program is equipped with a mechanism to read the data of these tables from pre-saved files in addition to the mechanism of saving the information entered in files that the user name and location to retrieve later, using the Open, Save buttons at the top of each table. The program is effectively and reliably protected against errors caused by inserting table information into another table. After entering information manually or in a saved file, the interface will look like Figure 4. 


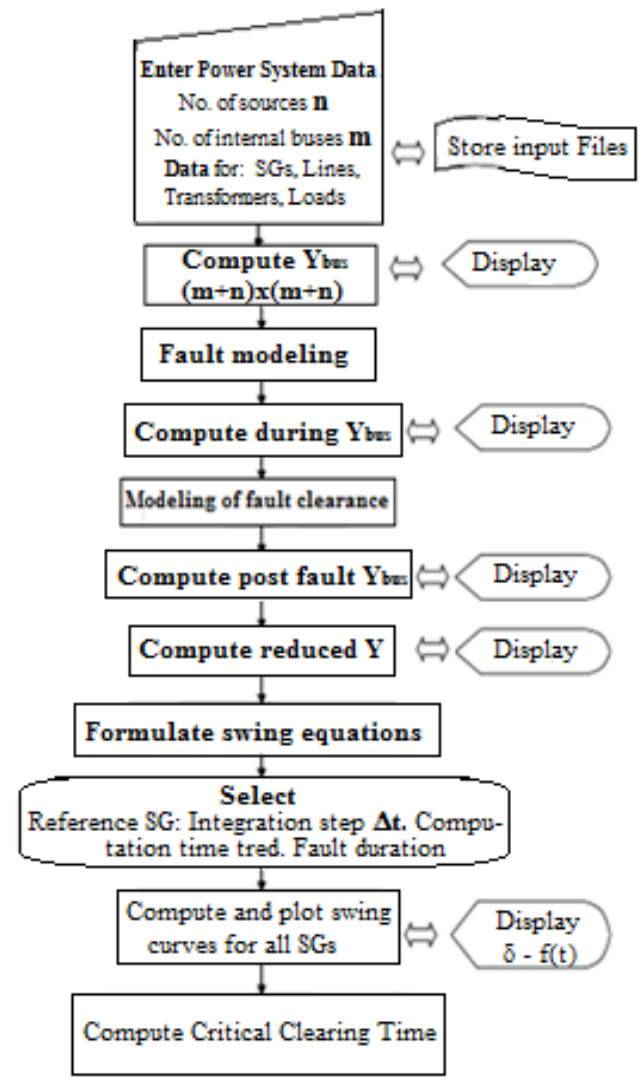

Figur 2. Flow Chart for the developed program

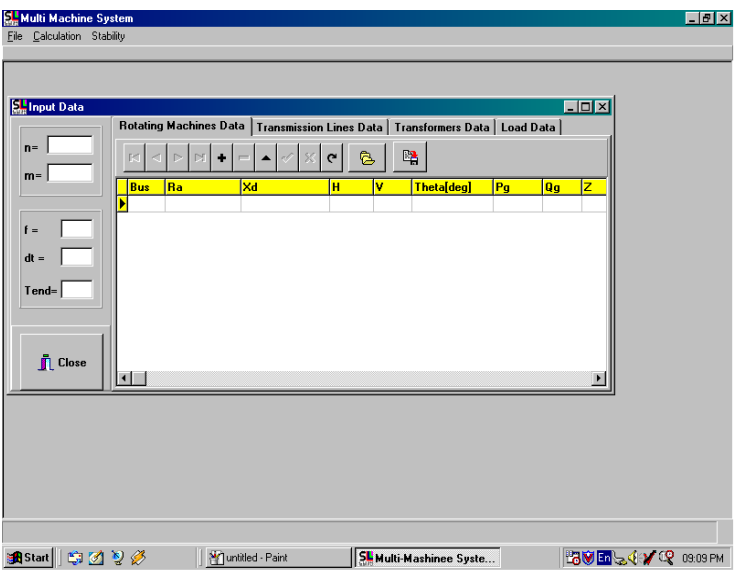

Figure 3. Main program window interface

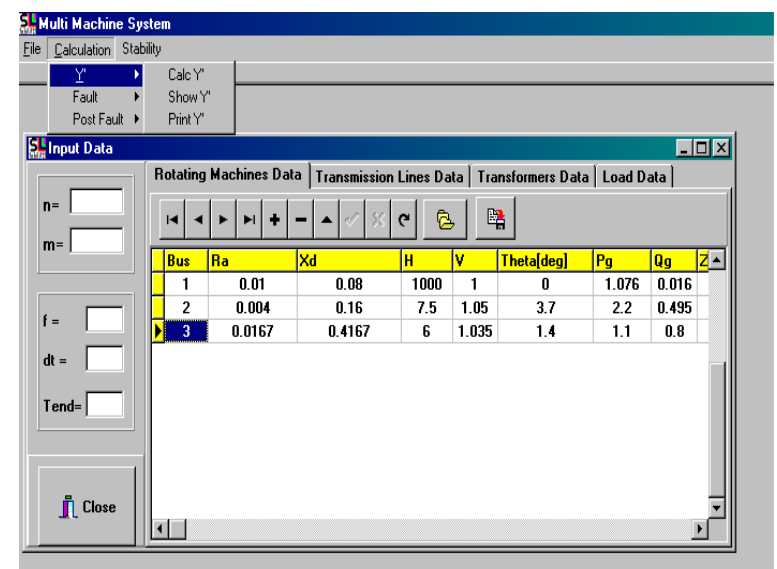

Figure 4. Main program window when entering machine data

The system's characteristic matrices $\left[Y^{\prime}\right]$ and $[Y]$ before, during and after the fault are computed as explained below:

a. By clicking "cal $\boldsymbol{Y}^{\prime \prime \prime}$, the prefault $\left[Y^{\prime}\right]$ will be computed, and by "show $\boldsymbol{Y}^{\prime \prime \prime}$ command the computed matrix can be displayed (Figure 5).

b. In order to compute the faulted $\left[Y^{\prime}\right]$, the fault must be first selected from the Calculation menu as follows:

Enter the number of buses that have occurred between them $(i, j)$ and a factor a (where a is a real number greater than zero and less than one) that determines the location of the fault. This is provided by the following window that appears automatically when the Calculation $\left[Y^{\prime}\right]$ command is clicked from the Fault menu (Figure 6). 


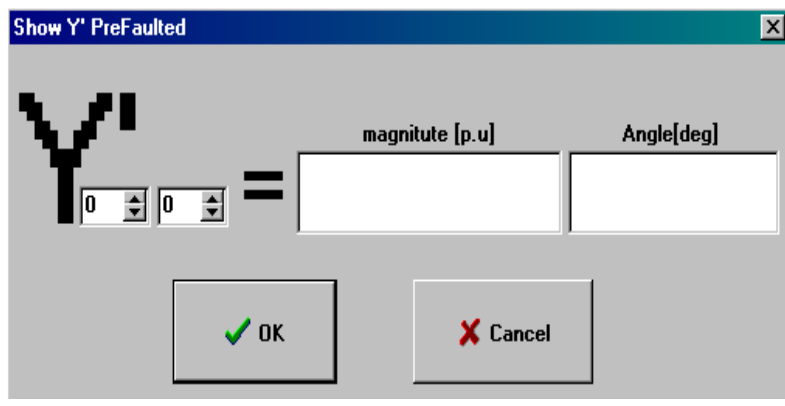

Figure 5. Display of the computed elements of [Y ']

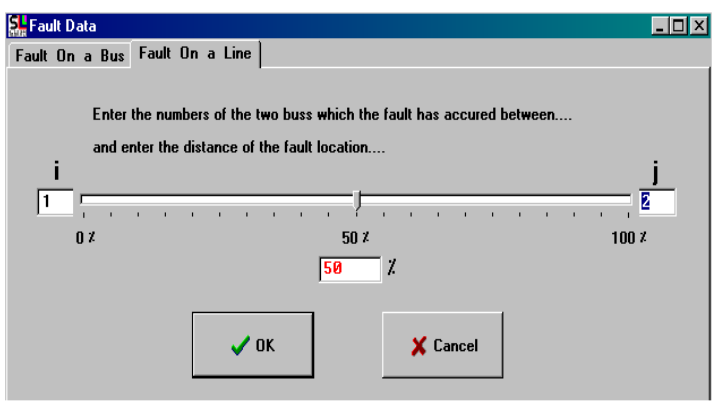

Figure 6. The mask for determining the fault location (the faulted branch and distance of fault point from one of branch buses)

A fault occurrence will cause a change of some elements of prefault $\left[Y^{\prime}\right]$. Thus, to obtain the faulted $\left[Y^{\prime}\right]$, the changed matrix elements that are affected by the fault are computed according to the following developed procedure:

$$
\begin{aligned}
& Y_{i j}^{\prime \text { new }}=0 \\
& Y_{i j}^{\prime \text { new }}=Y_{i j}^{\prime \text { old }}-Y_{i j}+\frac{1}{\alpha Z_{i j}}=Y_{i j}^{\prime o l d}-Y_{i j}+\frac{1}{\alpha} Y_{i j}=Y_{i j}^{\prime o l d}-\left(1+\frac{1}{\alpha}\right) Y_{i j} \\
& Y_{i j}^{\prime \text { new }}=Y_{i j}^{\prime \text { old }}-Y_{i j}+\frac{1}{(1-\alpha) Z_{i j}}=Y_{i j}^{\prime \text { old }}-Y_{i j}+\frac{1}{1-\alpha} Y_{i j} \\
& =Y_{i j}^{\prime \text { old }}-\left(1+\frac{1}{1-\alpha}\right) Y_{i j}
\end{aligned}
$$

where $Y^{\prime}$ is an element of $\left[Y^{\prime}\right]$ and $Y_{i j}$ is the natural admittance of faulted branch $i j$.

a. The postfault $\left[Y^{\prime}\right]$ is computed by using the computed prefault $\left[Y^{\prime}\right]$ with modified elements affected by fault clearance according to the following developed procedure:

$$
\begin{aligned}
& Y_{i j}^{\prime \text { new }}=0 \\
& Y_{i i}^{\prime \text { new }}=Y_{i i}^{\prime \text { old }}-Y_{i j}=Y_{i i}^{\prime \text { old }}-Y j_{i j}^{\prime \text { old }} \\
& Y_{j j}^{\prime \text { new }}=Y_{j j}^{\prime \text { old }}-Y_{i j}=Y_{j j i}^{\prime \text { old }}-Y_{i j}^{\prime \text { old }}
\end{aligned}
$$

b. The three reduced matrices $[Y]$ are computed from the stored three matrices $\left[Y^{\prime}\right]$ by the menu "Stability" and can be displayed as shown in Figure 7.

c. At this point, sufficient initial information is computed to study the stability of the machines of this system by clicking "Stability Calc" from the Stability menu. A mask will appear to be filled in by data required for the numerical solution method as shown in Figure 8.

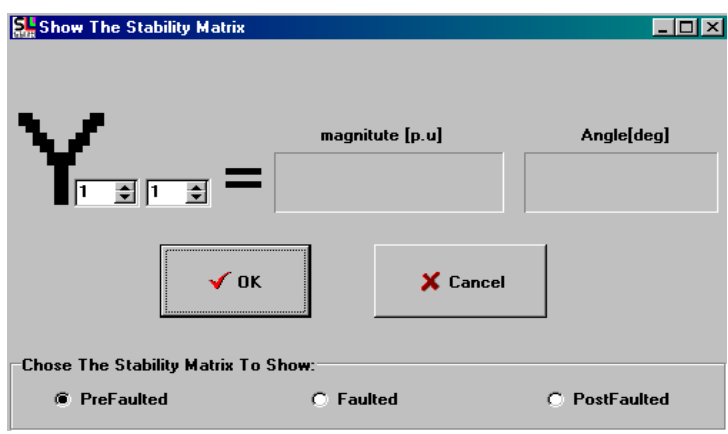

Figure 7. Display window for the three matrices [Y]

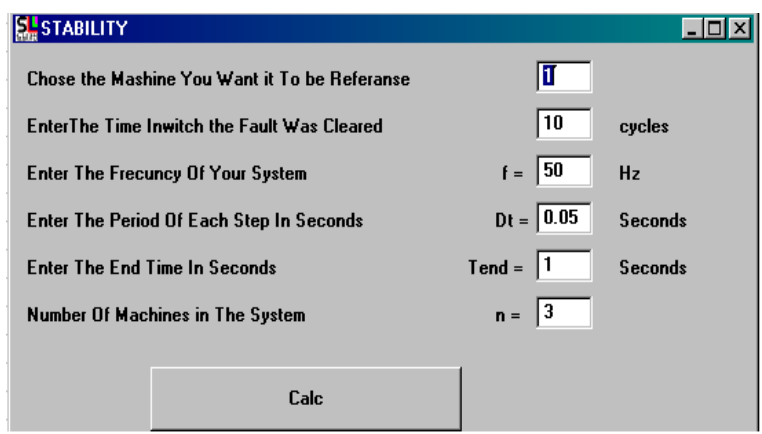

Figure 8. Mask to be filled in with final information required for numerical solution method 


\section{ILLUSTRATIVE SYSTEM EXAMPLE}

We consider a 50-Hz power system comprising 3 machines (two generators and an infinite bus), 16 buses, 9 transmission lines, and 7 loads as shown in Figure 9. The data for generators, transmission lines, transformers, and loads are given for the test system under consideration in per unit based on 100 MVA and voltage bases written on Figure 9. A wide range of case studies have been carried out by the developed program with balanced faults occurring on different locations and cleared at different times. The main results are swing curves of the 3 machines showing stable or unstable operation and the critical clearing time as well for the considered fault. Two case studies will be presented.

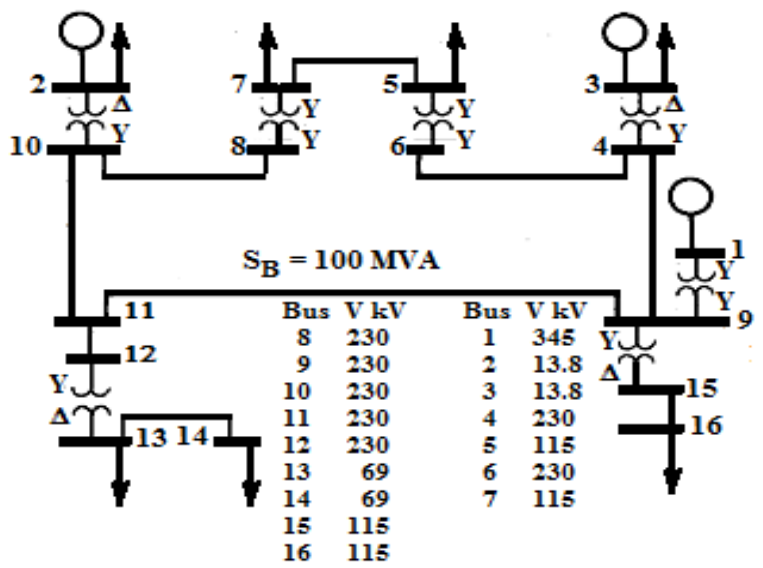

Figure 9. One-line diagram of three machine power system.

\section{Case study 1}

Assume that a balanced fault occurs on the line between buses 11 and 9 at a location very close to the bus 11 (2\% of the line length from bus 11). We try to find the critical clearing time for this fault by trial and error method. The computation results show that the last stable operation is possible for fault clearing time $T c=0.20 \mathrm{sec}$ as shown in Figure 10. If the clearing time is longer by a half cycle $(10 \mathrm{~ms})$ the operation becomes unstable for at least machine 2 as Figure 11 shows. This is logical because the fault is closer to the generator 2. When moving the fault location away from bus 11 as if it is in the middle of the line, the critical clearing time rises to $0.26 \mathrm{sec}$.

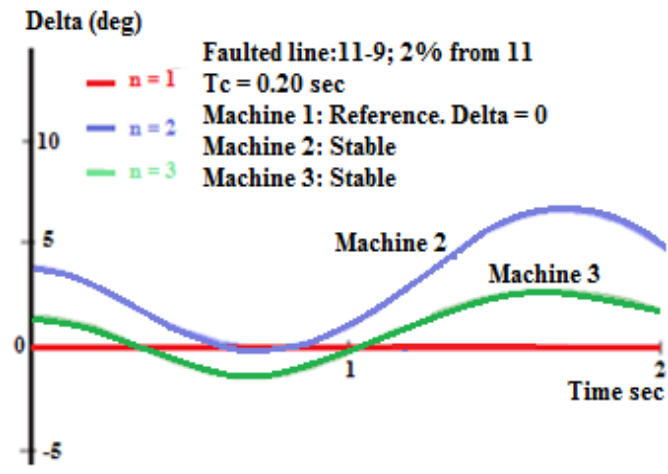

Figure 10. Swing curves for a fault on Line 9-11 ( $2 \%$ from 11) for clearing time $\mathrm{TC}=0.20 \mathrm{sec}$.

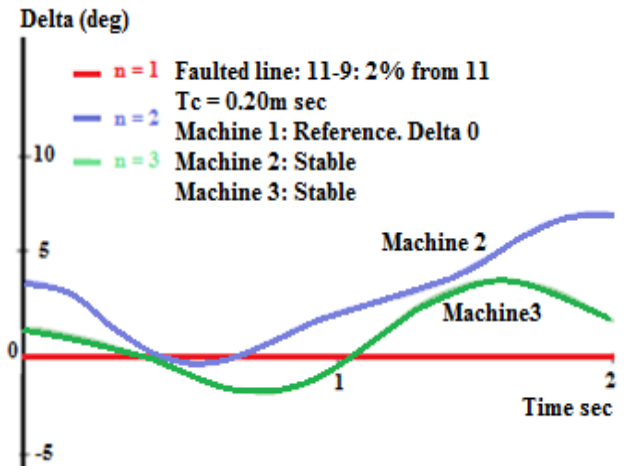

Figure 11. Swing curves for a fault on Line 9-11 ( $2 \%$ from 11$)$ for clearing time $\mathrm{TC}=0.21 \mathrm{sec}$.

\section{Case study 2}

Suppose a balanced fault occurs at the middle of the line between the buses 11 and 12 . Through a number of program runs with different fault clearing times $\left(T_{C}\right)$, the critical clearing time $\left(T_{C C}\right)$ for this fault is found to be $0.25 \mathrm{sec}$ (Figure 12). To verify this result, the program is run with $T_{C}=0.26 \mathrm{sec}$, meaning 10 
ms longer than $0.25 \mathrm{sec}$. The computed swing curves show that the operation of both generators becomes unstable (Figure 13).

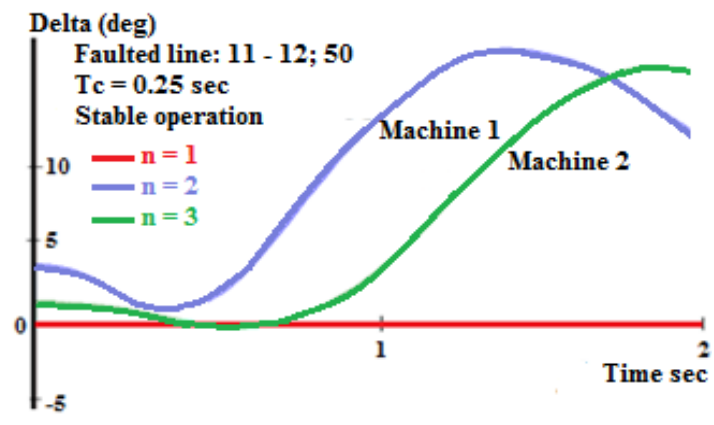

Figure 12. Swing curves for a fault on Line 11-12 (50\% from 11) for clearing time $\mathrm{TC}=0.25 \mathrm{sec}$.

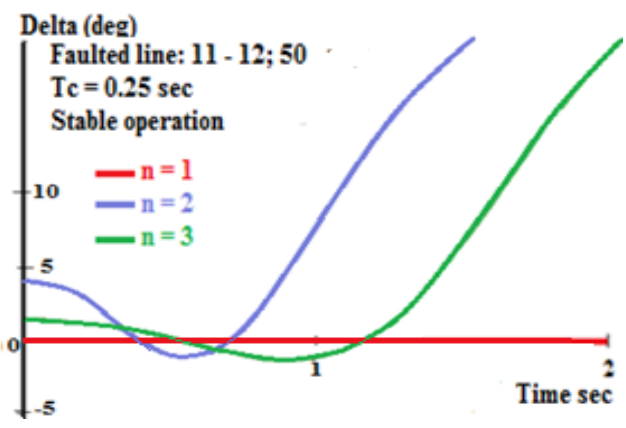

Figure 13. Swing curves for a fault on Line 11-12 ( $50 \%$ from 11) for clearing time $\mathrm{TC}=0.26 \mathrm{sec}$.

\section{CONCLUSIONS}

The outcome of this paper is a computer program in Delphi environment which is based on a newly improved mathematical model and a developed general algorithm for investigation of TS in multimachine electric power systems. The program is capable of studying the TS of an electrical power system consisting of an unlimited number of synchronous generators. It has been designed to provide a flexible and efficient dialogue environment for the user, through which the swing curves of all machines and consequently the critical clearing time of a fault can be found very quickly.

The program was used to study the TS of a relatively large test network and accurate results were obtained that could be relied upon for protective relays settings and optimization of control system parameters. The developed program can be extended in a future work to include generator control systems and to study their impact on improving stability as well as using more accurate models of synchronous generators.

\section{REFERENCES}

[1] Meenakshi De, G. Das, And K. K. Manda, "A new approach for investigation of multi machine stability in a Power system”, Indian J.Sci.Res. 14 (2): 245-249, 2017

[2] S. K. Gupta, Power System Operation Control \& Restructuring, I.K. International Publishing Pvt. Ltd, 2015

[3] Glover, M. Sarma, T. Overbuy, Power system analysis \& design, Cengage Learning, 2012

[4] P. M. Anderson, A. A. Fouad, Power System Control and Stability, Wiley Interscience, 2003

[5] Abdelkrim Zebar, Khaled Zehar, "Coordinated Control of SFCL and SVC for Power System Transient Stability Improvement”, TELKOMNIKA Indonesian Journal of Electrical Engineering, Vol. 13, No. 3, March 2015, pp.431440.

[6] Yorozu, M. Hirano, K. J. J. Grainer, W.D. Stevenson JR: Power System Analysis, McGraw-Hill International Editions, 1999.

[7] PSS-NETOMAC, https://www.energy.siemens.com

[8] DIgSILENT PowerFactory, https://www.digsilent.de/en/features-553.html

[9] A. Hamzeh, S. Hamed, Z. Al-Omari, A. Sandouk, G. Aldahim, "First Year Performance of a PV Plant in Jordan Compared to PV Plants in the Region", International Journal of Renewable Energy Research (IJRER), Vol.5, No.4, 2015, pp 983-990

[10] Al-Omari Z., "Influence of Control Modes of Grid-Connected Solar Photovoltaic Generation on Grid Power Flow", Engineering 2014, 6, 914-922. http://dx.doi.org/10.4236/eng.

[11] A. Hamzeh, A. Sandouk, "Impact of Integrated Hybrid PV/Wind Generation on Harmonic Power Flow in MediumVoltage Grid", Book Chapter 8 Pages 81-92, book "Renewable Energy in the Service of Mankind Vol II", Springer International Publishing Switzerland (C)2016

[12] A. Hamzeh, S. Hamed, Z. Al-Omari, A. Sandouk, G. Aldahim, "First Year Performance of a PV Plant in Jordan Compared to PV Plants in the Region", Book Chapter 62 Pages 785-798, book "Mediterranean Green Buildings \& Renewable Energy, Springer International Publishing Switzerland (C)2017

[13] Zakaria Al-Omari, A. Hamzeh, Sadeq A. Hamed, A. Sandouk, G. Aldahim, "A Mathematical Model for Minimizing Add-On Operational Cost in Electrical Power Systems Using Design of Experiments Approach", International Journal of Electrical and Computer Engineering (IJECE), Vol.5, No.5, 2015, pp 948-956.

[14] A. Hamzeh, S. Hamed, Z. Al-Omari, "Wind Generation Impact on Symmetrical Fault Level at Grid Buses", International Journal of Electrical and Computer Engineering (IJECE), Vol.8, No.5, 2015 
[15] N. M. Al-Rawi, A. Anwar, and A. M. Abdul-Majeed, "Computer Aided Transient Stability Analysis", Journal of Computer Science 3 (3): 149-153, 2007

[16] M. A. Salam, M. A. Rashid, Q. M. Rahman and M. Rizon "Transient Stability Analysis of a Three-machine Nine Bus Power System Network”, Engineering Letters, 22:1, EL_22_1_01, 2014.

[17] H. C. Duy, H. Q. Minh, and H. D. Loc, "Transient stability analysis of a multi machine Power system", www.nsl.hcmus.edu.vn/greenstone/collect/hnkhbk/archives/HASH2725.dir/doc.pdf

[18] A.E. Leon, J. M. Mauricio, J. A. Solsona, "Multi-machine power system stability improvement using an observerbased nonlinear controller", Electric Power Systems Research, Volume 89, August 2012, Pages 204-214

[19] B. Sebastian, R. Garg, "Transient stability analysis of multi-machine power system and first swing stability analysis using SVC", International Conference on Advances in Electrical Engineering (ICAEE), 2014

[20] T. T. Nguyen, A. Karimishad, "Transient Stability-constrained Optimal Power Flow for Online Dispatch and Nodal Price Evaluation in Power Systems with Flexible AC Transmission System Devices", IET Generation, Transmission and Distribution, Vol. 5, No. 3, 2011, pp. 332-346.

[21] A. Chaudhary, R. Jaswa," Transient Stability Improvement of Multi Machine Power System Using Static VAR compensator",International Journal of Electronic and Electrical Engineering. Volume 7, Number 2(2014),pp.109114.

[22] G. Pasala, R. Prabhakar:” A series fuzzy controller for first swing stability Enhancement in multi machine Power system", IEEE 2013

[23] H. Saadat, Power system analysis, PSA Publishing, 2010

[24] Ch. A. Gross, Power system analysis, John Wiley \& Sons 1996

[25] A. Gomez-Exposito, A. Conejo, C. Canizares, Electric energy systems analysis and operation, CRC Press 2009

[26] A. Hamzeh, K. Zaidan, Power system analysis, Damascus University Press, 2008

\section{BIOGRAPHIES OF AUTHORS}

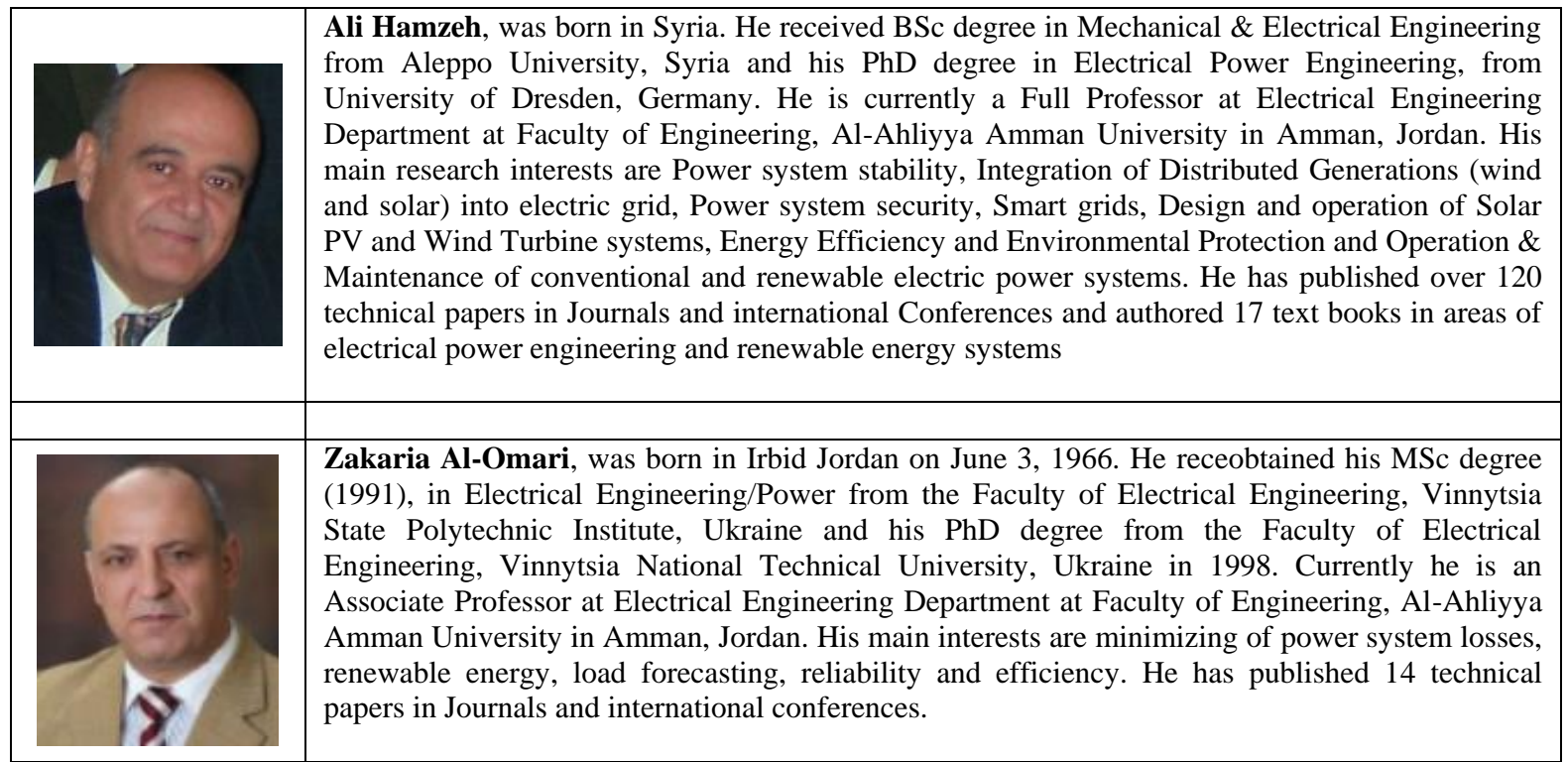

